\title{
Características micromorfológicas de biótipos de capim-arroz resistente e suscetível ao quinclorac
}

\author{
Evander Alves Ferreira( ${ }^{(1)}$, Germani Concenço(2), Leandro Galon(3), Marina Neves Delgado(4), Ignacio Aspiazú( ${ }^{(5)}$, \\ Alexandre Ferreira da Silva(6), Francisco Affonso Ferreira( ${ }^{(2)}$ e Renata Maria Strozi Alves Meira ${ }^{(2)}$
}

\begin{abstract}
(1)Universidade Federal dos Vales do Jequitinhonha e Mucuri, Faculdade de Ciências Agrárias, Rodovia MG 367, no 5.000, Alto do Jacuba, CEP 39100-000 Diamantina, MG. E-mail: evanderalves@yahoo.com.br (2)Universidade Federal de Viçosa, Avenida P.H. Rolfs, s/no, Campus Universitário, CEP 36570-000 Viçosa, MG. E-mail: gconcenco@yahoo.com.br, faffonso@ufv.br, rmeira@ufv.br (3)Universidade Federal da Fronteira Sul, Campus Erechim, Avenida Dom João Hoffmann, no 313, CEP 99700-000 Erechim, RS. E-mail: leandro.galon@uffs.edu.br (4)Universidade de Brasília, Campus Universitário Darcy Ribeiro, CEP 70910-900 Brasília, DF. E-mail: mnevesdelgado@gmail.com (5)Universidade Estadual de Montes Claros, CEP 39401-089 Janaúba, MG. E-mail: aspiazu@gmail.com ${ }^{(6)}$ Embrapa Milho e Sorgo, Rodovia MG 424, Km 45, CEP 35701-970 Sete Lagoas, MG. E-mail: alexandre.silva@cnpms.embrapa.br
\end{abstract}

Resumo - O objetivo deste trabalho foi avaliar o efeito do quinclorac nas características anatômicas de folhas e raízes de biótipos de capim-arroz (Echinochloa spp.), resistente e suscetível a este herbicida, por meio de avaliações micromorfométricas. As plantas foram cultivadas em vasos de plástico com capacidade de $250 \mathrm{~cm}^{3}$. As imagens dos cortes foram obtidas com microscópio de luz equipado com sistema U-Photo, acoplado à câmera digital conectada a microcomputador. Na seção transversal da lâmina foliar e das raízes, utilizouse objetiva de $10 \mathrm{X}$, tendo-se avaliado 20 cortes/campos por planta, com dez medições por corte e quatro repetições por tratamento. Observaram-se diferenças entre os biótipos resistente e suscetível, tanto na ausência quanto na presença do quinclorac. O biótipo resistente apresenta lâmina foliar pouco afetada pelo herbicida; no entanto, há modificação na constituição dos tecidos radiculares com a formação mais acentuada de aerênquima. O biótipo suscetível também apresenta formação de aerênquima quando tratado com o quinclorac, mas em quantidade inferior à observada no biótipo resistente.

Termos para indexação: Echinochloa, Oryza sativa, análises micromorfométricas.

\section{Micromorphological characteristics of barnyardgrass biotypes resistant and susceptible to quinclorac}

\begin{abstract}
The objective of this work was to evaluate the effect of quinclorac on anatomical traits of leaves and roots of barnyardgrass (Echinochloa spp.) biotypes, susceptible and resistant to this herbicide, by micromorphometric assessments. Plants were grown in plastic pots with $250 \mathrm{~cm}^{3}$ capacity. The images of plant sections were obtained with a light microscope equipped with a U-Photo system, coupled to a digital photo camera connected to a microcomputer. For cross-sections of leaf blades and roots, 10X objectives were used, and 20 sections/fields per plant were evaluated, with ten measurements per section and four replicates per treatment. Differences were observed between resistant and susceptible biotypes, both in the absence and in the presence of quinclorac. The resistant biotype shows leaf blades that are less affected by the herbicide; however, there are changes in root tissue constitution with increased aerenchyma formation. The susceptible biotype also shows formation of aerenchyma when treated with quinclorac, but in lower levels than those observed for the resistant biotype.
\end{abstract}

Index terms: Echinochloa, Oryza sativa, micromorphometric analyses.

\section{Introdução}

O gênero Echinochloa, conhecido vulgarmente como capim-arroz, apresenta diversas espécies que causam severos prejuízos à agricultura mundial, ao infestar mais de 36 culturas, em 61 países (Norris et al., 2001). O controle das espécies desse gênero, em lavouras de arroz irrigado, tornou-se prática obrigatória, e geralmente é realizado com herbicidas aplicados em pré ou pós-emergência dessas plantas daninhas ou da cultura (Lopez-Martinez et al., 1997; Concenço et al., 2009; Galon \& Agostinetto, 2009). O elevado uso de herbicidas para o controle de plantas daninhas, em arroz irrigado, deve-se à praticidade, à alta eficiência e, principalmente, à dificuldade de uso de outros métodos de controle após a inundação da lavoura, em que se 
aplica lâmina de água que inviabiliza a entrada de maquinário.

No Brasil, o capim-arroz infesta e está distribuído na grande maioria das lavouras do Rio Grande do Sul e de Santa Catarina, onde se destaca como uma das principais plantas daninhas que compete com a cultura do arroz (Oryza sativa L.) (Andres et al., 2007; Galon et al., 2007; Tironi et al., 2009). Os efeitos negativos da infestação do capim-arroz na cultura podem ser atribuídos à alta capacidade de competição com as plantas de arroz por recursos limitantes do meio, à dificuldade de controle, ao aumento do custo de produção, ao acamamento das plantas da cultura, à dificuldade de colheita, à depreciação da qualidade do produto, à hospedagem de pragas, à redução do valor comercial das áreas cultivadas e ao surgimento da resistência a herbicidas (Lopez-Martinez et al., 1997; Andres et al., 2007; Concenço et al., 2009; Galon \& Agostinetto, 2009).

Em razão do uso contínuo de herbicidas com o mesmo mecanismo de ação, quase sempre na ausência de rotação de culturas e de manejo integrado das plantas daninhas, populações de capim-arroz desenvolveram resistência a vários herbicidas (Ruiz-Santaella et al., 2003; Concenço et al., 2009), e alguns biótipos têm apresentado resistência múltipla (Lopez-Martinez et al., 1997). No Brasil, biótipos de capim-arroz resistentes ao quinclorac estão amplamente distribuídos nos estados do Rio Grande do Sul e de Santa Catarina, onde se concentra cerca de $70 \%$ da produção nacional de arroz (Concenço et al., 2009; Tironi et al., 2009). Além disso, estudos preliminares indicam que os biótipos resistentes apresentam ampla variação morfofisiológica, e que, provavelmente, a resistência se desenvolveu de modo independente nas diferentes regiões produtoras de arroz (Andres et al., 2007; Concenço et al., 2009).

O quinclorac é um herbicida recomendado para o controle de capim-arroze de angiquinho(Aeschynomene denticulata Rudd), em pós-emergência, nas lavouras de arroz irrigado do Brasil. Esse herbicida é classificado como mimetizador de auxinas, pertencente ao grupo químico do ácido quinolínico (Grossmann \& Kwiatkowski, 2000; Andres et al., 2007). Os sintomas de intoxicação ocasionados pelo quinclorac às plantas daninhas ocorrem entre o sétimo e o décimo dia após a aplicação, na forma de pontos vermelho-escuros, com clorose seguida da morte das plantas (Grossmann \& Kwiatkowski, 2000).
Esse herbicida é seletivo para um número conhecido de espécies, como arroz, milho, sorgo e pastagens. Contudo, seu modo de ação e mecanismo de seletividade ainda não são bem conhecidos (Grossmann \& Kwiatkowski, 2000). Segundo Zheng \& Hall (2001), o sítio de ação do quinclorac é um grupo de proteínas conhecidas como ABP ("auxin-binding proteins"). Estes autores realizaram a caracterização bioquímica e fisiológica da resistência de biótipos de Sinapis arvensis L. [Brassica kaber (DC.) L.C. Wheeler] a herbicidas com este mecanismo de ação e verificaram diferenças quanto à absorção, à translocação e ao metabolismo, entre biótipos resistentes e suscetíveis.

$\mathrm{Na}$ literatura, foram observados níveis de resistência (valores de $\mathrm{RI}_{50}$ ) de populações de capim-arroz entre 6, 10 e 26 (López-Martínez et al., 1997), e até superior a 128 vezes mais altos que os do biótipo suscetível (Concenço et al., 2009), o que indica distintos mecanismos de resistência entre os biótipos. Abdallah et al. (2006) observaram alta capacidade de desintoxicação de cianida em biótipos de Digitaria ischaemum (Schreb.) Muhl., com intensificação na presença de quinclorac, ao se considerar que os sintomas do quinclorac diferem dos observados com a aplicação de outros herbicidas auxínicos (Sunohara \& Matsumoto, 1997).

Os herbicidas influenciam o crescimento vegetal ao inibir a ação de enzimas ou impedir a formação de alguma estrutura necessária para a multiplicação e o crescimento da célula (Silva et al., 2007). Diferenças morfofisiológicas entre biótipos de azevém resistente e suscetível ao herbicida glifosato, por exemplo, resultaram em menor taxa de transporte de água das raízes à parte aérea de plantas do biótipo resistente (Concenço et al., 2007).

Quanto a caracteres anatômicos, Hamza et al. (2012) concluíram que biótipos de capim-arroz (E. crusgalli) resistentes ao herbicida fenoxaprop-ethyl apresentaram diferenças marcantes na citologia, em comparação ao biótipo resistente, em relação à espessura da lâmina foliar e ao diâmetro dos vasos do xilema, o que poderia contribuir para a menor translocação do produto, embora esta não esteja entre as causas mais prováveis da resistência naquele biótipo. Assim, alterações nas estruturas internas da planta podem contribuir para desvendar o real mecanismo de resistência de um biótipo de planta daninha a determinado herbicida. 
$\mathrm{Na}$ literatura, são poucas as informações sobre os possíveis efeitos nas características micromorfológicas dos biótipos resistentes, ocasionados pelo mecanismo de resistência desenvolvido pela planta.

O objetivo deste trabalho foi avaliar o efeito do quinclorac nas características anatômicas de folhas e raízes de biótipos de capim-arroz, resistente e suscetível a este herbicida, por meio de avaliações micromorfométricas.

\section{Material e Métodos}

O experimento foi instalado em novembro de 2008, em casa de vegetação, pertencente ao Departamento de Fitotecnia da Universidade Federal de Viçosa (UFV), MG $\left(20^{\circ} 45^{\prime} 31^{\prime \prime} \mathrm{S}\right.$ e $42^{\circ} 51^{\prime} 31^{\prime \prime} \mathrm{W}$, a $662 \mathrm{~m}$ de altitude), com temperatura entre 22 e $27^{\circ} \mathrm{C}$ e iluminação natural. $\mathrm{O}$ clima da região, segundo a classificação de Köppen, é do tipo Cwa, mesotérmico úmido, com verões quentes e invernos secos.

As sementes de capim-arroz foram semeadas em vasos de plástico, com capacidade de $250 \mathrm{~cm}^{3}$, preenchidos com substrato livre de qualquer contaminação. Após a emergência, realizou-se $o$ desbaste, tendo-se deixado apenas uma planta por vaso. Foram aplicados fertilizantes contendo macro e micronutrientes a partir da emergência das plantas até 30 dias após a aplicação dos tratamentos, o que foi feito a cada dez dias. As unidades experimentais foram mantidas inundadas durante o experimento, com lâmina de água na altura de $1 \mathrm{~cm}$ da base dos colmos das plantas de capim-arroz.

Utilizou-se o delineamento experimental completamente casualizado, com quatro repetições, e os tratamentos foram dispostos em arranjo fatorial $2 \times 2$. $\mathrm{O}$ fator A foi composto pelos biótipos de capim-arroz resistente (ECH-13) e suscetível (ECH-12) ao quinclorac; o fator $\mathrm{B}$ foi representado pelos tratamentos com e sem aplicação do herbicida.

Dez dias após a emergência das plantas, quando estas apresentavam duas a três folhas, aplicou-se o herbicida quinclorac $\left(0,375 \mathrm{~kg} \mathrm{ha}^{-1}\right)$. O herbicida foi aplicado com pulverizador costal pressurizado a $\mathrm{CO}_{2}$, acoplado à barra contendo ponta de pulverização da série TT 110.02, com aspersão de volume de calda de $150 \mathrm{~L} \mathrm{ha}^{-1}$.

Vinte dias após a aplicação dos tratamentos, foram coletadas as raízes e as primeiras folhas, com limbo foliar totalmente expandido e com lígula visível, que foram armazenadas diretamente em FAA 70\% - formaldeído + ácido acético glacial + álcool 70\% (Johansen, 1940) - e transportadas ao Laboratório de Anatomia Vegetal do Departamento de Biologia Vegetal da UFV.

Porções de $0,5 \mathrm{~cm}^{2}$ da região mediana das folhas e cerca de $10 \mathrm{~mm}$ de raízes coletadas a $5 \mathrm{~cm}$ do ápice radicular foram desidratadas em série etílica, incluídas em historesina, de acordo com recomendações do fabricante (Historesin, Leica Instruments, Heidelberg, Alemanha), e cortadas transversalmente em micrótomo rotativo de avanço automático, com navalhas de aço, com $8 \mu \mathrm{m}$ de espessura. O material foi corado com azul de toluidina $\mathrm{pH}$ 4,0 (O'Brien et al., 1964) e montado em resina sintética.

As imagens digitalizadas dos cortes foram obtidas com microscópio de luz, modelo AX70TRF (Olympus Optical Co., Ltd., Tokyo, Japão), equipado com sistema U-Photo, acoplado à câmera digital conectada a microcomputador. Para a obtenção dos dados de área e medidas lineares, utilizou-se o programa Image-Pro Plus 4.5 (Media Cybernetics, Inc., Rockville, MD, EUA).

Na seção transversal da lâmina foliar e das raízes, utilizou-se objetiva de 10X, e, em cada lâmina foliar ou raiz dos biótipos resistente ou suscetível do capim-arroz, foram avaliados 20 cortes (20 campos), tendo-se realizado, em cada corte, dez medições, com quatro repetições. Os dados de área das folhas e das raízes foram transformados em percentagem, em relação à área total. Na lâmina foliar, foram determinadas as seguintes características: espessura da epiderme adaxial (EED), espessura da epiderme abaxial (EEB), espessura da lâmina foliar (ELF), diâmetro do feixe central (DFC), diâmetro do feixe secundário (DFS), distância entre feixes (DEF), percentagem de epiderme adaxial (\%EPD), percentagem de epiderme abaxial (\%EPB), percentagem de células buliformes (\%CBL), percentagem de bainha do feixe vascular $(\% \mathrm{BFV})$, percentagem de feixes vasculares (\%FXV), percentagem de esclerênquima (\%ESC) e percentagem de mesofilo (\%MES).

As características determinadas na seção transversal das raízes foram: diâmetro da raiz (DAR), espessura do córtex ou aerênquima (ECX), espessura dos feixes vasculares (EAF), diâmetro da medula (DAM), percentagem de epiderme (\%EPI), percentagem de 
córtex ou aerênquima (\%CTA), percentagem de feixes vasculares $(\% \mathrm{FVS})$ e percentagem de medula (\%MED).

Os dados foram submetidos à análise de variância pelo teste $\mathrm{F}$, a $5 \%$ de probabilidade, e, quando significativas, as médias foram comparadas pelo teste $\mathrm{t}$, também a $5 \%$ de probabilidade.

\section{Resultados e Discussão}

As folhas são anfiestomáticas e apresentam células buliformes e anatomia do tipo Kranz, com o mesofilo dividindo-se em células da bainha, circundadas por células do mesofilo (Figura 1). O biótipo suscetível, na presença do herbicida, apresentou redução no tamanho da seção transversal da folha, com modificações nos tecidos, como alterações no tamanho e na forma das células buliformes.
Observaram-se diferenças significativas nas raízes dos biótipos de capim-arroz, principalmente na presença do quinclorac (Figura 2). Houve a formação de aerênquima no córtex das raízes, e, na ausência do produto, foi observada a presença de células parenquimáticas neste mesmo tecido. No caso do biótipo suscetível, verificou-se redução no diâmetro das raízes com a formação de aerênquima, enquanto, no biótipo resistente, houve a formação de aerênquima, mas sem modificação no diâmetro das raízes. Jesus et al. (2009), ao trabalhar com efeito de resíduos industriais em Cyperus rotundus L., verificaram que, nas plantas intoxicadas, os mesofilos tornaram-se estreitos com lacunas pequenas, e a estrutura de Kranz indicou alterações de aproximadamente $50 \%$ no número de cloroplastos.

Não foi observada diferença entre os biótipos e os tratamentos com e sem herbicida quanto à espessura das células epidérmicas das faces adaxial e abaxial (EED

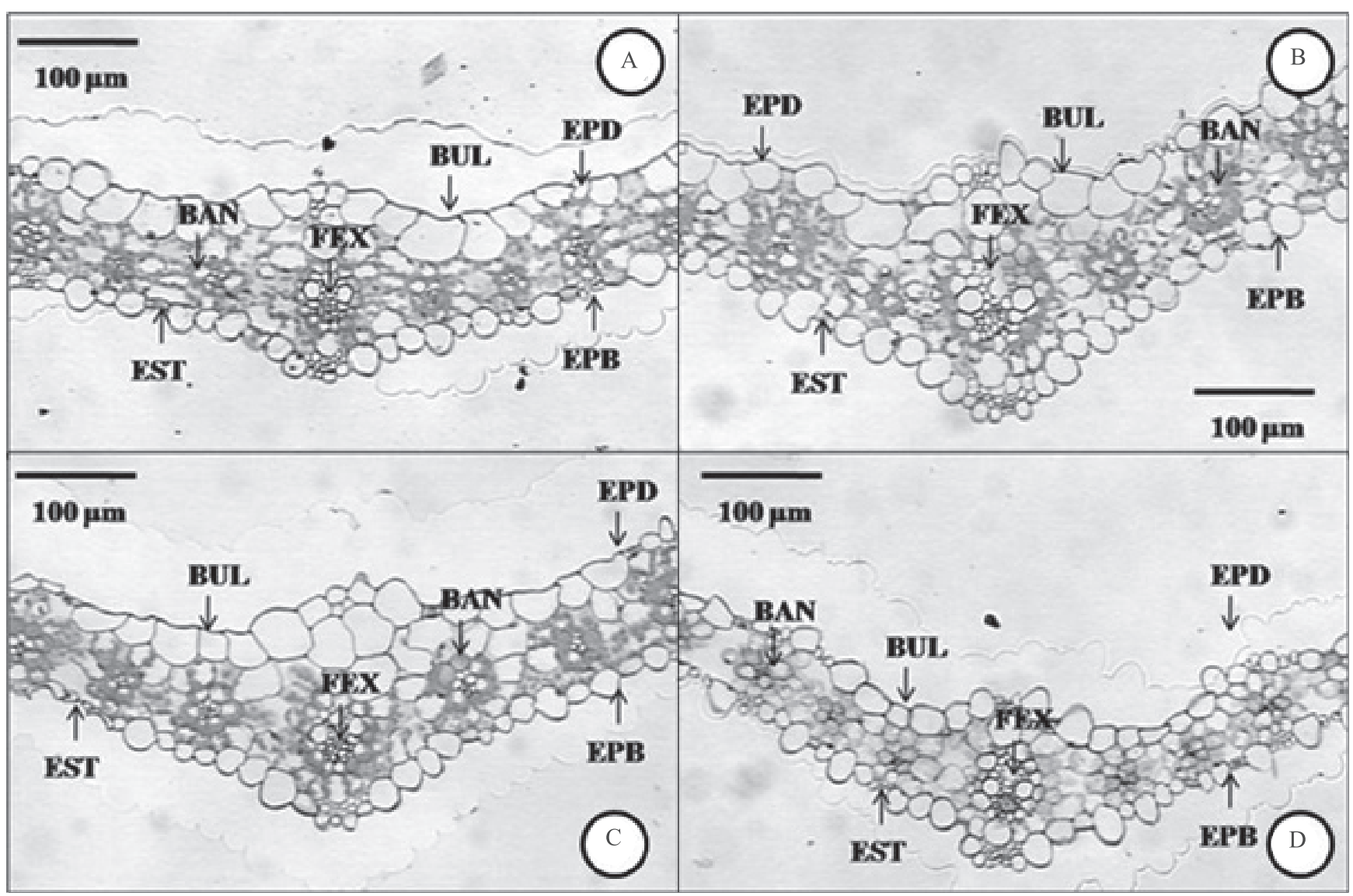

Figura 1. Seção transversal da lâmina foliar de biótipos de capim-arroz resistente (A) e suscetível (B) sem herbicida, e resistente (C) e suscetível (D) com herbicida quinclorac. BUL, células buliformes; EST, estômato; FEX, feixe vascular; BAN, bainha do feixe vascular; EPD, epiderme da face adaxial; EPB, epiderme da face abaxial. 
e EEB) da lâmina foliar de capim-arroz (Tabela 1). No entanto, Môro et al. (1999), ao avaliar os efeitos do herbicida nicosulfuron em cultivares de milho, verificaram que as principais alterações anatômicas observadas nos tecidos foliares restringiram-se às células componentes do sistema dérmico e que não foram evidenciadas alterações celulares no mesofilo. Fialho et al. (2009) também relataram redução significativa da epiderme na face abaxial e adaxial em Urochloa brizantha (Hochst. ex A. Rich) R.D. Webster submetida ao tratamento com trinexapac-ethyl.

O biótipo suscetível apresentou maior espessura da lâmina foliar (ELF), quando comparado ao resistente, na ausência do quinclorac; no entanto, na presença do herbicida, a ELF foi superior no biótipo resistente (Tabela 1). Fialho et al. (2009), ao avaliar o efeito do regulador de crescimento trinexapac-ethyl em $U$. brizantha, observaram que as características relacionadas a medições lineares realizadas no mesofilo (porção central da folha), a espessura da lâmina foliar, o diâmetro do feixe central e a distância entre feixes apresentaram aumento para o tratamento com o regulador de crescimento. Dessa forma, como o quinclorac também é essencialmente um regulador de crescimento, quando aplicado em plantas tolerantes, pode levar ao espessamento da lâmina foliar.

O biótipo suscetível sem aplicação do herbicida apresentou maior diâmetro do feixe central (DFC), em comparação ao biótipo resistente. Já na presença do herbicida, houve redução no DFC no biótipo suscetível e incremento no resistente.

O biótipo suscetível, na ausência de quinclorac, apresentou maior distância entre feixes (DEF), quando comparado ao resistente. Na presença do herbicida,

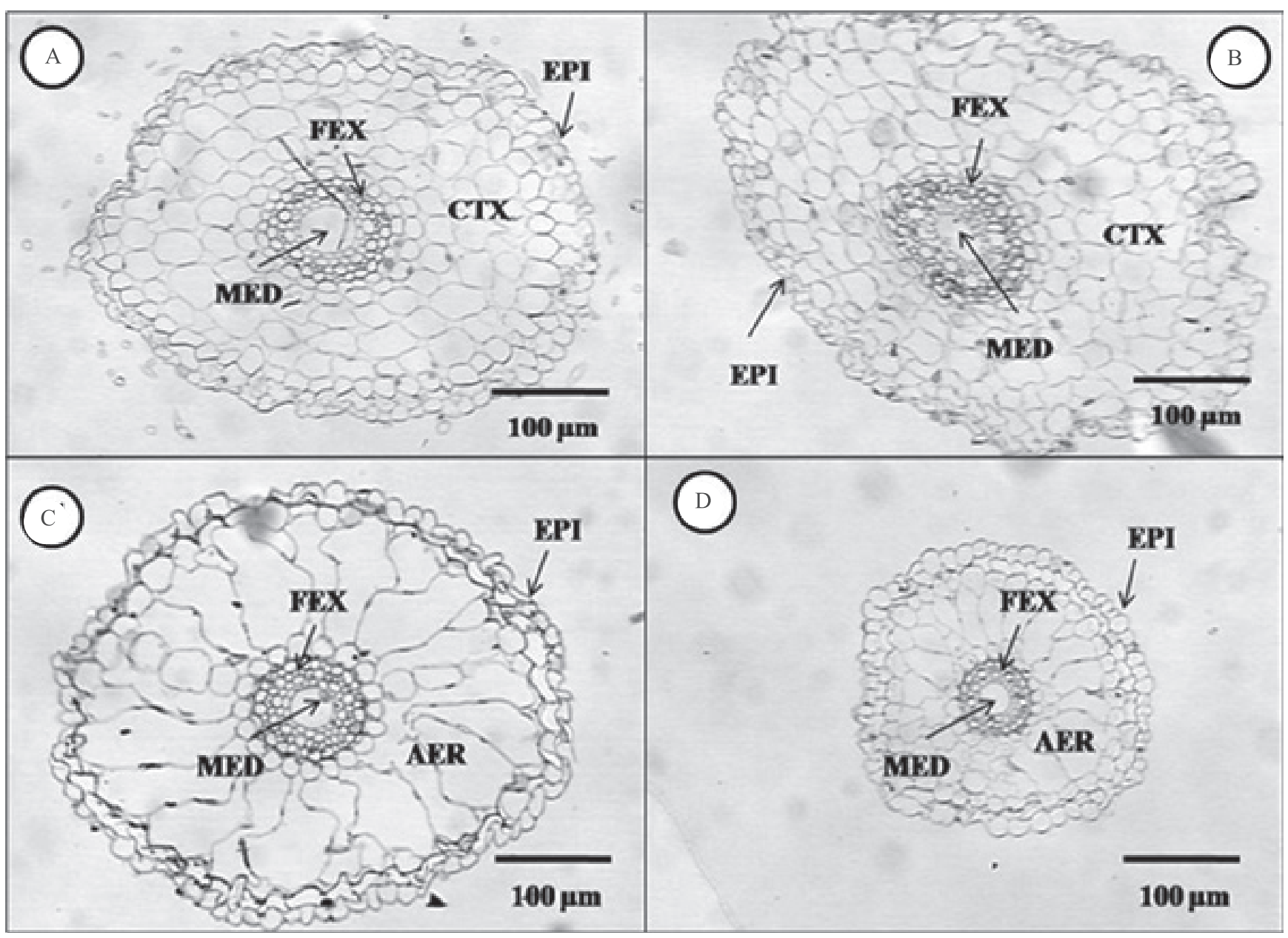

Figura 2. Seção transversal de raízes de biótipos de capim arroz resistente (A) e suscetível (B) sem herbicida, e resistente (C) e suscetível (D) com herbicida quinclorac. EPI, epiderme; FEX, feixes vasculares; CTX, córtex; e MED, medula. 
observou-se redução da DEF na lâmina foliar do biótipo suscetível e aumento da DEF no biótipo resistente (Tabela 1). A menor distância entre os feixes vasculares está relacionada à maior vascularização das folhas, com consequente aumento da capacidade de transporte de fotoassimilados e água (Ferreira et al., 2003; Ferreira, 2007).

Ao avaliar a proporção de células epidérmicas na superfície adaxial da lâmina foliar de capim-arroz (\%EPD), constatou-se que o biótipo resistente, na ausência do quinclorac, apresentou maior valor dessa variável em comparação ao suscetível; porém, nos tratamentos que receberam o produto, não foi

Tabela 1. Valores médios de espessura da epiderme adaxial (EED), espessura da epiderme abaxial (EEB), espessura da lâmina foliar (ELF), diâmetro do feixe central (DFC), diâmetro do feixe secundário (DFS), distância entre feixes (DEF) e percentagem de epiderme adaxial (\%EPD), de epiderme abaxial (\%EPB), de células buliformes (\%CBL), de bainha do feixe vascular (\%BFV), de esclerênquima (\%ESC) e de mesofilo (\%MES) das folhas de biótipos de capim-arroz resistente (R) e suscetível (S) ao quinclorac, sem $(\mathrm{SH})$ e com $(\mathrm{CH})$ aplicação de herbicida ${ }^{(1)}$.

\begin{tabular}{|c|c|c|c|c|}
\hline Caractere & Suscetibilidade & $\mathrm{SH}$ & $\mathrm{CH}$ & $\mathrm{CV}(\%)$ \\
\hline \multicolumn{5}{|c|}{ Tamanho $(\mu \mathrm{m})$} \\
\hline \multirow{2}{*}{ EED } & $\mathrm{S}$ & $21,7 \mathrm{aA}^{1}$ & $23,0 \mathrm{aA}$ & \multirow{2}{*}{11,8} \\
\hline & $\mathrm{R}$ & $24,5 \mathrm{aA}$ & $24,0 \mathrm{aA}$ & \\
\hline \multirow{2}{*}{ EEB } & S & $19,7 \mathrm{aA}$ & $18,2 \mathrm{aA}$ & \multirow{2}{*}{16,5} \\
\hline & $\mathrm{R}$ & $19,2 \mathrm{aA}$ & $19,0 \mathrm{aA}$ & \\
\hline \multirow{2}{*}{ ELF } & S & $103,7 \mathrm{aA}$ & $88,0 \mathrm{bB}$ & \multirow{2}{*}{5,8} \\
\hline & $\mathrm{R}$ & $99,2 \mathrm{aB}$ & $116,5 \mathrm{aA}$ & \\
\hline \multirow{2}{*}{ DFC } & S & $64,2 \mathrm{aA}$ & $52,5 \mathrm{aB}$ & \multirow{2}{*}{12,8} \\
\hline & $\mathrm{R}$ & $38,7 \mathrm{bB}$ & $50,2 \mathrm{aA}$ & \\
\hline \multirow{2}{*}{ DFS } & S & $39,5 \mathrm{aB}$ & $31,2 \mathrm{aA}$ & \multirow{2}{*}{10,1} \\
\hline & $\mathrm{R}$ & $26,0 \mathrm{bB}$ & $31,0 \mathrm{aA}$ & \\
\hline \multirow{2}{*}{ DEF } & S & $47,0 \mathrm{aB}$ & $40,0 \mathrm{bA}$ & \multirow{2}{*}{9,2} \\
\hline & $\mathrm{R}$ & $38,5 \mathrm{bB}$ & $47,7 \mathrm{aA}$ & \\
\hline \multicolumn{5}{|c|}{ Percentagem } \\
\hline \multirow{2}{*}{$\%$ EPD } & S & $19,0 \mathrm{bB}$ & $27,7 \mathrm{aA}$ & \multirow{2}{*}{11,0} \\
\hline & $\mathrm{R}$ & $22,7 \mathrm{aA}$ & $18,7 \mathrm{bB}$ & \\
\hline \multirow{2}{*}{$\%$ ЕРВ } & S & $17,2 \mathrm{aA}$ & $17,7 \mathrm{aA}$ & \multirow{2}{*}{15,9} \\
\hline & $\mathrm{R}$ & $17,3 \mathrm{aA}$ & $14,7 \mathrm{aA}$ & \\
\hline \multirow{2}{*}{$\% \mathrm{CBL}$} & S & $9,0 \mathrm{aA}$ & $6,2 \mathrm{aA}$ & \multirow{2}{*}{23,4} \\
\hline & $\mathrm{R}$ & $8,0 \mathrm{aA}$ & $7,7 \mathrm{aA}$ & \\
\hline \multirow{2}{*}{$\% \mathrm{BFV}$} & S & $7,2 \mathrm{aA}$ & $4,7 \mathrm{aB}$ & \multirow{2}{*}{11,7} \\
\hline & $\mathrm{R}$ & $5,2 \mathrm{bA}$ & $5,5 \mathrm{aA}$ & \\
\hline \multirow{2}{*}{$\% \mathrm{ESC}$} & S & $1,2 \mathrm{aA}$ & $1,5 \mathrm{aA}$ & \multirow{2}{*}{20,2} \\
\hline & $\mathrm{R}$ & $1,1 \mathrm{aA}$ & $1,0 \mathrm{aA}$ & \\
\hline \multirow{2}{*}{$\%$ MES } & S & $46,0 \mathrm{bA}$ & $42,2 \mathrm{bA}$ & \multirow{2}{*}{5,8} \\
\hline & $\mathrm{R}$ & $52,7 \mathrm{aA}$ & $52,0 \mathrm{aA}$ & \\
\hline
\end{tabular}

${ }^{(1)}$ Médias seguidas de letras iguais, minúsculas nas linhas e maiúsculas nas colunas, não diferem, entre si, pelo teste t, a $5 \%$ de probabilidade. observada diferença entre os biótipos (Tabela 1). Assim, observou-se mudança na proporção deste tecido, tanto no biótipo suscetível quanto no resistente, com aplicação do quinclorac. Ao se usar o herbicida nicosulfuron em cultivares de milho, verificou-se aumento considerável no número, no tamanho e na forma das células buliformes em ambas as faces da lâmina foliar, com desaparecimento quase total de células epidérmicas fundamentais (Môro et al., 1999).

Com relação à proporção de epiderme na face abaxial $(\% \mathrm{EPB})$ e à proporção de células buliformes $(\% \mathrm{CBL})$, não foram observadas diferenças entre os biótipos e os tratamentos com e sem herbicida. As células buliformes formam faixas de diferentes larguras na superfície foliar. Estas células são, geralmente, descritas como células motoras, envolvidas no processo de enrolamento e desenrolamento das folhas (Ferreira et al., 2007). Fialho et al. (2009) observaram diferença para as medidas relacionadas à proporção de tecidos na lâmina foliar de $U$. brizantha tratada com trinexapac-ethyl, em que tecidos, como o mesofilo, feixes vasculares e células buliformes, tiveram suas proporções alteradas.

O biótipo suscetível apresentou maior proporção de feixes vasculares (\%FXV), quando comparado ao resistente sem aplicação do quinclorac, e, na presença do herbicida, não foi constatada diferença entre os biótipos. O biótipo suscetível mostrou decréscimo da $\% \mathrm{FXV}$ na presença do produto, o que caracteriza mudança na proporção desse tecido ao se aplicar o quinclorac, e não foi observada alteração no biótipo resistente com e sem herbicida (Tabela 1). Quanto à proporção de esclerênquima (\%ESC), não houve diferença significativa entre os biótipos com e sem o herbicida e as gramíneas do tipo $\mathrm{C}_{4}$, caracterizadas por elevadas proporções de feixes vasculares, esclerênquima e bainha parenquimática dos feixes (Paciullo et al., 2002).

Nas raízes, o biótipo resistente apresentou maior proporção de mesofilo (\%MES), em comparação ao suscetível, tanto na ausência quanto na presença do quinclorac (Tabela 2). No entanto, observou-se decréscimo da \%MES no biótipo suscetível submetido à aplicação do herbicida. Não houve alteração na \%MES do biótipo resistente com e sem herbicida.

Foram observadas alterações marcantes nas raízes dos biótipos resistente e suscetível, quando submetidos ao tratamento com o quinclorac. O biótipo suscetível, sem a aplicação do herbicida, mostrou maior diâmetro de raiz (DAR), quando comparado ao resistente, e 
essa mesma variável foi maior no biótipo resistente na presença do quinclorac. Entretanto, ao se compararem os tratamentos com e sem herbicida dentro dos biótipos, observou-se que, no suscetível, ocorreu decréscimo do DAR na presença do produto e, no resistente, ocorreu o inverso.

O biótipo suscetível de capim-arroz, sem aplicação de herbicida, apresentou maior espessura do córtex (ECX), em comparação ao resistente (Tabela 2); porém, na presença de herbicida, o biótipo suscetível apresentou menor ECX.

Não houve diferença significativa entre os biótipos resistente e suscetível quanto à espessura dos feixes vasculares (EAF). Contudo, na presença do quinclorac, o biótipo resistente apresentou maior EAF do que o suscetível, e o herbicida afetou negativamente o biótipo resistente e o suscetível.

Tanto na presença quanto na ausência do quinclorac, o biótipo resistente apresentou maior diâmetro da medula (DAM) do que o suscetível. Com relação à aplicação dos tratamentos dentro de cada biótipo,

Tabela 2. Valores médios de diâmetro da raiz (DAR), espessura do córtex ou aerênquima (ECX), espessura dos feixes vasculares (EAF), diâmetro da medula (DAM) e de percentagem de epiderme (\%EPI), de córtex ou aerênquima (\%CTA), de feixes vasculares (\%FVS) e de medula (\%MED) das raízes de biótipos de capim-arroz resistente (R) e suscetível (S) ao quinclorac sem (SH) ou com $(\mathrm{CH})$ aplicação do herbicida ${ }^{(1)}$.

\begin{tabular}{|c|c|c|c|c|}
\hline Caractere & Suscetibilidade & $\mathrm{SH}$ & $\mathrm{CH}$ & CV $(\%)$ \\
\hline \multicolumn{5}{|c|}{ Tamanho $(\mu \mathrm{m})$} \\
\hline \multirow{2}{*}{ DAR } & S & $374,7 \mathrm{aA}$ & $222,5 \mathrm{bB}$ & \multirow{2}{*}{2,7} \\
\hline & $\mathrm{R}$ & $341,7 \mathrm{bB}$ & $363,0 \mathrm{aA}$ & \\
\hline \multirow{2}{*}{ ECX } & S & $115,0 \mathrm{aA}$ & $58,5 \mathrm{bB}$ & \multirow{2}{*}{4,9} \\
\hline & $\mathrm{R}$ & $96,7 \mathrm{bA}$ & $102,7 \mathrm{aA}$ & \\
\hline \multirow{2}{*}{ EAF } & S & $107,7 \mathrm{aA}$ & $54,0 \mathrm{bB}$ & \multirow{2}{*}{3,6} \\
\hline & $\mathrm{R}$ & $88,0 \mathrm{aA}$ & $82,5 \mathrm{aB}$ & \\
\hline \multirow{2}{*}{ DAM } & S & $30,2 \mathrm{bA}$ & $18,2 \mathrm{bB}$ & \multirow{2}{*}{10,6} \\
\hline & $\mathrm{R}$ & $39,5 \mathrm{aA}$ & $30,5 \mathrm{aA}$ & \\
\hline \multicolumn{5}{|c|}{ Percentagem } \\
\hline \multirow{2}{*}{$\%$ EPI } & S & $12,7 \mathrm{aB}$ & $19,5 \mathrm{aA}$ & \multirow{2}{*}{16,2} \\
\hline & $\mathrm{R}$ & $9,7 \mathrm{bB}^{1}$ & $13,7 \mathrm{bA}$ & \\
\hline \multirow{2}{*}{$\% \mathrm{CTA}$} & $\mathrm{S}$ & $72,7 \mathrm{aA}$ & $72,5 \mathrm{bA}$ & \multirow{2}{*}{4,2} \\
\hline & $\mathrm{R}$ & $66,2 \mathrm{bB}$ & $77,5 \mathrm{aA}$ & \\
\hline \multirow{2}{*}{$\% \mathrm{FVS}$} & S & $13,0 \mathrm{aA}$ & $6,5 \mathrm{aB}$ & \multirow{2}{*}{13} \\
\hline & $\mathrm{R}$ & $14,0 \mathrm{aA}$ & $7,7 \mathrm{aB}$ & \\
\hline \multirow{2}{*}{$\%$ MED } & S & $6,5 \mathrm{bA}$ & $1,2 \mathrm{aB}$ & \multirow{2}{*}{17,3} \\
\hline & $\mathrm{R}$ & $10,7 \mathrm{aA}$ & $1,0 \mathrm{aB}$ & \\
\hline
\end{tabular}

(1)Médias seguidas de letras iguais, minúsculas nas linhas e maiúsculas nas colunas, não diferem pelo teste t, a $5 \%$ de probabilidade. houve redução do DAM no suscetível, mas não foi observada diferença no resistente.

Hamza et al. (2012), ao avaliar alterações anatômicas e fisiológicas de biótipos de E.crus-galli (L.), resistente e suscetível ao fenoxaprop-p-ethyl, observaram alterações quanto ao efeito do herbicida nos biótipos e em relação à variável em estudo, o que confirma os resultados obtidos no presente trabalho.

Houve mudança na proporção da maioria dos tecidos de raízes avaliados quando as plantas foram submetidas ao tratamento com o quinclorac (Tabela 2). O biótipo suscetível mostrou maior proporção de epiderme (\%EPI) nas raízes, em comparação ao resistente, em ambos os tratamentos. Além disso, ambos os biótipos apresentaram incremento da \%EPI na presença do herbicida.

O biótipo suscetível apresentou maior proporção de córtex (\%CTA) na ausência do produto, mas, na presença do herbicida, não houve diferença entre os biótipos. Em muitas espécies que se desenvolvem em habitat inundado ou mesmo úmido, como o arroz e o arroz-daninho (arroz-vermelho ou preto), as células estão separadas por espaços proeminentes preenchidos de ar, que formam o tecido denominado aerênquima, desenvolvido nas raízes destas plantas, independentemente dos estímulos ambientais, mas cuja proporção pode aumentar quando as plantas crescem em ambiente inundado. No entanto, em poucas plantas não nativas destes ambientes úmidos, a deficiência de oxigênio induz à formação de aerênquima na base do caule e em células novas, como ocorre no capim-arroz, que pode tolerar condições estritamente anaeróbicas por um período de tempo prolongado (semanas e meses) até desenvolver aerênquima (Taiz \& Zeiger, 2009).

Em ambiente hipóxico, a diminuição nos níveis de oxigênio desencadeia uma cascata de sinais que afeta o metabolismo de produção de etileno (Grandis et al., 2010). He et al. (1996), ao avaliar plantas de milho, observaram que, quando ocorre hipóxia das raízes, há aumento na síntese de etileno pelo aumento da atividade de acetil carboxilase sintase (ACC sintase), o que resulta em aumento na atividade de celulase que contribui para a degradação da parede celular e a formação de aerênquima do tipo lisígeno.

Em alguns casos, a auxina e o etileno provocam respostas semelhantes nas plantas, o que pode ser atribuído à capacidade das auxinas em promover a 
síntese de etileno pelo aumento da atividade da ACC sintase (Taiz \& Zeiger, 2009). Dessa forma, ao se considerar que o quinclorac é um herbicida semelhante às auxinas, a formação de aerênquima nos dois biótipos avaliados pode estar relacionada.

Tanto na presença quanto na ausência do herbicida, não foi observada diferença entre os biótipos de capim-arroz com relação à proporção de feixes vasculares (\%FVS); no entanto, constatou-se redução da \%FVS no biótipo resistente e no suscetível sob aplicação do herbicida (Tabela 2). Os feixes vasculares são responsáveis pelo transporte de água e sais minerais (xilema), bem como de fotossintatos (floema), assim, qualquer modificação nesses tecidos pode levar à redução na eficiência de transporte tanto no xilema quanto no floema, o que reduz o potencial competitivo do biótipo resistente na presença do herbicida. Costa et al. (2012), ao trabalhar com o herbicida glifosato (que apresenta mecanismo de ação diferente do quinclorac) aplicado em $U$. distachya (L.) T.Q. Nguyen [Brachiaria subquadripara (Trin.) Hitchc.], verificaram que as principais alterações anatômicas do limbo foliar foram o aumento da percentagem do feixe vascular e a diminuição da percentagem de esclerênquima.

Observou-se que o biótipo resistente apresentou maior proporção de tecido medular (\%MED) do que o biótipo suscetível na ausência do produto; entretanto, na presença do quinclorac, não houve diferença significativa entre os biótipos. Verificou-se decréscimo da \%MED, nos dois biótipos, nos tratamentos que receberam aplicação do herbicida (Tabela 2). Este decréscimo na proporção da medula nas raízes pode ser explicado, no caso do biótipo resistente, pelo efeito do herbicida, que afeta em maior grau o biótipo suscetível. Resultados semelhantes foram relatados por Hamza et al. (2012).

\section{Conclusões}

1. Há diferenças nas características micromorfométricas avaliadas entre os biótipos resistente ou suscetível, tanto na ausência quanto na presença do herbicida quinclorac.

2. O biótipo resistente apresenta lâmina foliar pouco afetada pelo quinclorac; no entanto, observase modificação na constituição dos tecidos radiculares deste biótipo com a formação de aerênquima, quando submetido ao herbicida.
3. O biótipo suscetível também apresenta formação de aerênquima quando tratado com o quinclorac; contudo, os valores relacionados às características micromorfométricas observados nas raízes, como ECX, DAR e DAM, são inferiores aos obtidos no biótipo resistente.

\section{Agradecimentos}

À Fundação de Amparo à Pesquisa do Estado de Minas Gerais, à Coordenação de Aperfeiçoamento de Pessoal de Nível Superior e ao Conselho Nacional de Desenvolvimento Científico e Tecnológico, pelo apoio financeiro e pela concessão de bolsas.

\section{Referências}

ABDALLAH, I.; FISCHER, A.J.; ELMORE, C.; SALTVEIT, M.; ZAKI, M. Mechanism of resistance to quinclorac in smooth crabgrass (Digitaria ischaemum). Pesticide Biochemistry and Physiology, v.84, p.38-48, 2006.

ANDRES, A.; CONCENÇO, G.; MELO, P.T.B.S.; SCHMIDT, M.; RESENDE, R.G. Detecção da resistência de capim-arroz (Echinochloa sp.) ao herbicida quinclorac em regiões orizícolas do Sul do Brasil. Planta Daninha, v.25, p.221-226, 2007.

CONCENÇO, G.; FERREIRA, E.A.; SILVA, A.A.; FERREIRA, F.A.; VIANA, R.G.; D'ANTONINO, L.; VARGAS, L.; FIALHO, C.M.T. Uso da água em biótipos de azevém (Lolium multiflorum) em condição de competição. Planta Daninha, v.25, p.449-455, 2007.

CONCENÇO, G.; SILVA, A.F.; FERREIRA, E.A.; GALON, L.; NOLDIN, J.A.; ASPIAZÚ, I.; FERREIRA, F.A.; SILVA, A.A. Effect of dose and application site on quinclorac absorption by barnyardgrass biotypes. Planta Daninha, v.27, p.541-548, 2009.

COSTA, N.V.; MARTINS, D.; RODELLA, R.A.; RODRIGUES-COSTA, A.C.P. Alterações anatômicas foliares em plantas de Brachiaria subquadripara submetidas à aplicação de herbicidas. Planta Daninha, v.30, p.253-261, 2012.

FERREIRA, E.A.; PROCÓPIO, S.O.; SILVA, E.A.M.; SILVA, A.A.; RUFINO, R.J.N. Estudos anatômicos de folhas de espécies de plantas daninhas de grande ocorrência no Brasil: IV - Amaranthus deflexus, Amaranthus spinosus, Alternanthera tenella e Euphorbia heterophylla. Planta Daninha, v.21, p.263-271, 2003.

FERREIRA, E.A.; VENTRELLA, M.C.; SANTOS, J.B.; BARBOSA, M.H.P.; SILVA, A.A.; PROCÓPIO, S.O.; SILVA, E.A.M. Leaf blade quantitative anatomy of sugarcane cultivars and clones. Planta Daninha, v.25, p.25-34, 2007.

FIALHO, C.M.T.; FERREIRA, E.A.; MEIRA, R.A.S.; SANTOS, J.B.; SILVA, A.A.; FREITAS, F.C.L.; GALON, L.; CONCENÇO, G.; SILVA, A.F.; TIRONI, S.P.; ROCHA, P.R.R. Caracteres morfoanatômicos de Brachiaria brizantha submetida à aplicação de Trinexapac-Ethyl. Planta Daninha, v.27, p.533-539, 2009. 
GALON, L.; AGOSTINETTO, D. Comparison of empirical models for predicting yield loss of irrigated rice (Oryza sativa) mixed with Echinochloa spp. Crop Protection, v.28, p.825-830, 2009.

GALON, L.; AGOSTINETTO, D.; MORAES, P.V.D.; DAL MAGRO, T.; PANOZZO, L.E.; BRANDOLT, R.R.; SANTOS, L.S. Níveis de dano econômico para decisão de controle de capim-arroz (Echinochloa spp.) em arroz irrigado (Oryza sativa). Planta Daninha, v.25, p.709-718, 2007.

GRANDIS, A.; GODOI, S.; BUCKERIDGE, M.S. Respostas fisiológicas de plantas amazônicas de regiões alagadas às mudanças climáticas globais. Revista Brasileira de Botânica, v.33, p.1-12, 2010.

GROSSMANN, K.; KWIATKOWSKI, J. The mechanism of quinclorac selectivity in grasses. Pesticide Biochemistry and Physiology, v.66, p.83-91, 2000.

HAMZA, A.; DERBALAH, A.; EL-NADY, M. Identification and mechanism of Echinochloa crus-galli resistance to fenoxaprop-p-ethyl with respect to physiological and anatomical differences. The Scientific World Journal, v.2012, p.1-8, 2012.

HE, C.J.; MORGAN, P.W.; DREW, M.C. Transduction of an ethylene signal is required for cell death and lysis in the root cortex of maize during aerenchyma formation induced by hypoxia. Plant Physiology, v.112, p.463-472, 1996.

JESUS, S.L.; ARÉVALO, R.A.; ROMÃO, G.O.; ROSSI, L.M.; COSCIONE, A.R.; NOGUEIRA, N.L. Potencial de utilização de Cyperus rotundus na descontaminação de áreas de descarte de resíduos industriais com elevados teores de metais. Planta Daninha, v.27, p.641-645, 2009.

JOHANSEN, D.A. Plant microtechnique. New York: McGraw-Hill, 1940. 523p.

LOPEZ-MARTINEZ, N.; MARSHALL, G.; DEPRADO, R. Resistance of barnyardgrass (Echinochloa crus-galli) to atrazine and quinclorac. Pesticide Science, v.51, p.171-175, 1997.

MÔRO, F.V.; DAMIÃO FILHO, C.F. Alterações morfo-anatômicas das folhas de milho submetidas à aplicação de nicosulfuron. Planta Daninha, v.17, p.331-337, 1999.
NORRIS, R.F.; ELMORE, C.L.; REJMÁNEK, M.; AKEY, W.C. Spatial arrangement, density, and competition between barnyardgrass and tomato: I. Crop growth and yield. Weed Science, v.49, p.61-68, 2001.

O'BRIEN, T.P.; FEDER, N.; MCCULLY, M.E. Polychromatic staining of plant cell walls by toluidine blue. Protoplasma, v.59, p.368-373, 1964.

PACIULLO, D.S.C.; GOMIDE, J.A.; SILVA, E.A.M. da; QUEIROZ, D.S.; GOMIDE, C.A.M. Características anatômicas da lâmina foliar e do colmo de gramíneas forrageiras tropicais, em função do nível de inserção no perfilho, da idade e da estação de crescimento. Revista Brasileira de Zootecnia, v.31, p.890-899, 2002.

RUIZ-SANTAELLA, J.P.; FISCHER, A.J.; DE PRADO, R. Alternative control of two biotypes of Echinochloa phyllopogon susceptible and resistant to fenoxaprop-ethyl. Communications in Agricultural and Applied Biological Sciences, v.68, p.403-407, 2003.

SILVA, A.A. da; VARGAS, L.; FERREIRA, E.A. Herbicidas: resistência de plantas. In: SILVA, A.A. da; SILVA, J.F. da (Ed.). Tópicos em manejo de plantas daninhas. Viçosa: UFV, 2007. p.279-324.

SUNOHARA, Y.; MATSUMOTO, H. Comparative physiological effects of quinclorac and auxins, and light involvement in quinclorac-induced chlorosis in corn leaves. Pesticide Biochemistry and Physiology, v.58, p.125-132, 1997.

TAIZ, L.; ZEIGER, E. Fisiologia vegetal. 4.ed. Porto Alegre: Artmed, 2009. 848p.

TIRONI, S.P.; GALON, L.; CONCENÇO, G.; FERREIRA, E.A.; SILVA, A.F.; ASPIAZÚ, I.; FERREIRA, F.A.; SILVA, A.A.; NOLDIN, J.A. Habilidade competitiva de plantas de arroz com biótipos de capim-arroz resistente ou suscetível ao quinclorac. Planta Daninha, v.27, p.257-263, 2009.

ZHENG, H.G.; HALL, J.C. Understanding auxinic herbicide resistance in wild mustard: physiological, biochemical, and molecular genetic approaches. Weed Science, v.49, p.276-281, 2001.

$\overline{\text { Recebido em } 4 \text { de abril de } 2012 \text { e aprovado em } 13 \text { de julho de } 2012}$ 